\title{
POWER CONSUMING SYSTEM USING WSN IN HEMS
}

\author{
S.SAMA RUHIN ${ }^{1}$, T.SIVA KUMAR ${ }^{2}$, DR G.N.KODANDA RAMAIAH ${ }^{3}$ \\ ${ }^{I} P G$ Scholar, Dept of ECE, KEC, JNTU Anantapur, Andhrapradesh, India, E-mail: sama9ruhi@gmail.com \\ ${ }^{2}$ Asst Prof, Dept of ECE, KEC, JNTU Anantapur, Andhrapradesh, India, E-mail: sksivakumar990@gmail.com \\ ${ }^{3} H O D$, Dept of ECE, KEC, JNTU Anantapur, Andhrapradesh, India.
}

\begin{abstract}
Today's buildings account for a large fraction of our energy consumption. In an effort to economize scarce fossil fuels on earth, sensor networks are a valuable tool to increase the energy efficiency of buildings without severely reducing our quality of life. Within a smart building many sensors and actuators are interconnected to form a control system. Nowadays, the deployment of a building control system is complicated because of different communication standards. Here we present a web services-based approach to integrate resource constrained sensor and actuator nodes into IP-based networks. A key feature of our approach is its capability for automatic service discovery. The design and development of an intelligent monitoring and controlling system for home appliances in a real time system is reported in this paper. This system principally monitors the electrical parameters such as voltage and current and subsequently calculates the power consumption of the home appliances that are need to be monitored. The innovation of this system is controlling mechanism implementation in so many ways. Also the proposed system is an economical and easily operable. Due to these intelligent characteristics it become an electricity expense reducer and people friendly.
\end{abstract}

\section{INTRODUCTION}

It is foreseen that service and personal care wireless mechatronic systems will become more and more ubiquitous at home in the near future and will be very useful in assistive healthcare particularly for the elderly and disabled people. Wireless mechatronic systems consist of numerous spatially distributed sensors with limited data collection and processing capability to monitor the environmental situation. Wireless sensor networks (WSNs) have become increasingly important because of their ability to monitor and manage situational information for various intelligent services. Due to those advantages, WSNs has been applied in many fields, such as the military, industry, environmental monitoring, and healthcare. The WSNs are increasingly being used in the home for energy controlling services. Regular household appliances are monitored and controlled by WSNs installed in the home. New technologies include cutting-edge advancements in information technology, sensors, metering, transmission, distribution, and electricity storage technology, as well as providing new information and flexibility to both consumers and providers of electricity.

There are several proposals to interconnect various domestic appliances by wireless networks to monitor and control. But the prototypes are verified using test bed scenarios. Also, smart meter systems have been designed to specific usages particularly related to geographical usages and are limited to specific places. Different information and communication technologies integrating with smart meter devices have been proposed and tested at different flats in a residential area for optimal power utilization ,but individual controlling of the devices are limited to specific houses. There has been design and developments of smart meters predicting the usage of power consumption. However, a low-cost, flexible, and robust system to continuously monitor and control based on consumer requirements is at the early stages of development.

The paper focuses on human-friendly technical solutions for monitoring and easy control of household appliances. The inhabitant's comfort will be increased and better assistance can be provided. This paper emphasizes the realization of monitoring and controlling of electrical appliances in many ways.

The developed system has the following distinct features.

$>$ Use of relay drivers for controlling electrical appliances: Household appliances are controlled either remotely or automatically with the help of fabricated smart sensing unit consisting of relay .

$>$ Flexibility in controlling the appliances: Depending on the user requirements, appliances can be monitored and controlled in different ways.

\section{IMPLEMENTATION}




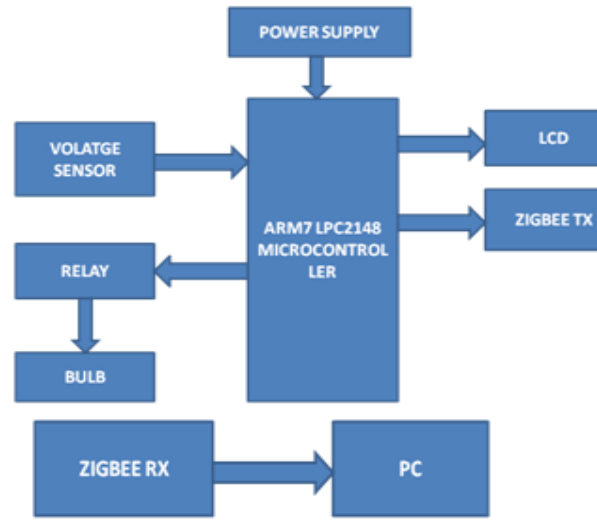

Fig.1

Figure 1 shows the implementation of our proposed system. The project concludes that the power consuming system based on the wsn is nothing but the wireless sensor networks. In our proposed system we focus on the power consumption and the security purposes and the protection of the electrical devices and this is totally developed and improved by the embedding in the wireless sensor networks in mainly home energy management systems. The voltage level is detected by voltage sensor, if there is any changes in the voltage level the automatically the load condition will also changes. All these information which is related to changes in voltage level will be uploaded to the pc by using zigbee module.

The main modules used here are:

1. ARM7 microcontroller

2. Zigbee module

\section{ARM7 Micro Controller:}

"ARM" is the abbreviation of "Advanced RISC Machines". It's a well known processor cores in the world. It is primarily used in portable gadgets because of reasonable efficiency and low power consumption. ARM is a family of RISC architectures. The ASK 16/32-bit ARM7TDMI-S microcontroller coaching board is very in particular designed to help scholars to meet their required advantage in the area of embedded techniques. It's possible to design the kit in such method that the entire major features of the micro controller will likely be fully used by the pupils.

\section{LPC2148 Chip Features:}

- 16-bit/32-bit ARM7TDMI-S microcontroller in a tiny LQFP64 package.

- $8 \mathrm{kB}$ to $40 \mathrm{kB}$ of on-chip static RAM and 32 $\mathrm{kB}$ to $512 \mathrm{kB}$ of on-chip flash memory.

- 128-bit wide interface/accelerator enables high-speed $60 \mathrm{MHz}$ operation.

- In-System Programming/In-Application Programming (ISP/IAP) via on-chip boot loader software. Single flash sector or full chip erase in $400 \mathrm{~ms}$ and programming 256 bytes in $1 \mathrm{~ms}$.

- Embedded ICE RT and Embedded Trace interfaces offer real-time debugging with the on-chip Real Monitor software and high-speed tracing of instruction execution.

- USB 2.0 Full-speed compliant device controller with $2 \mathrm{kB}$ of endpoint RAM.

- $\quad$ Single 10-bit DAC provides variable analog output (LPC2142/44/46/48 only).

- Two 32-bit timers/external event counters (with four capture and four compare channels each), PWM unit (six outputs) and watchdog.

- Low power Real-Time Clock (RTC) with independent power and $32 \mathrm{kHz}$ clock input.

- Multiple serial interfaces including two UARTs (16C550), two Fast I2C-bus (400 $\mathrm{kbit} / \mathrm{s})$,

- $\quad$ SPI and SSP with buffering and variable data length capabilities.

\section{ZIGBEE MODULE}

ZigBee Module is a low-cost, low-power, wireless mesh networking standard. The low cost allows the technology to be widely deployed in wireless control and monitoring applications, the low power-usage allows longer life with smaller batteries, and the mesh networking provides high reliability and larger range. This device network has the characteristics of electric power-saving, reliability, low cost, large capacity and security, and it can be widely used in various fields of automatic control. The target application domains are aimed at industry, home automation, telemetry and remote control, vehicle automation, agriculture automation, medical care and so on, such as lighting control automation, wireless data acquisition and monitoring sensor, oil field, electric power, mining and logistics management etc.

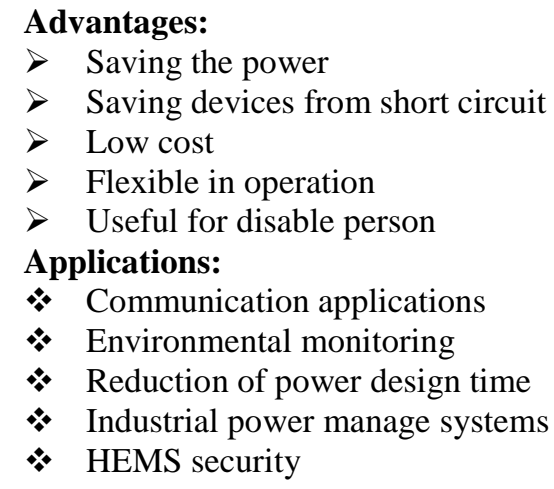

\section{RESULTS}

First connect all the wires as per the kit and and connect all the switches to the plug box and check again all the connection then switch on the power supply then the kit will be activated. 


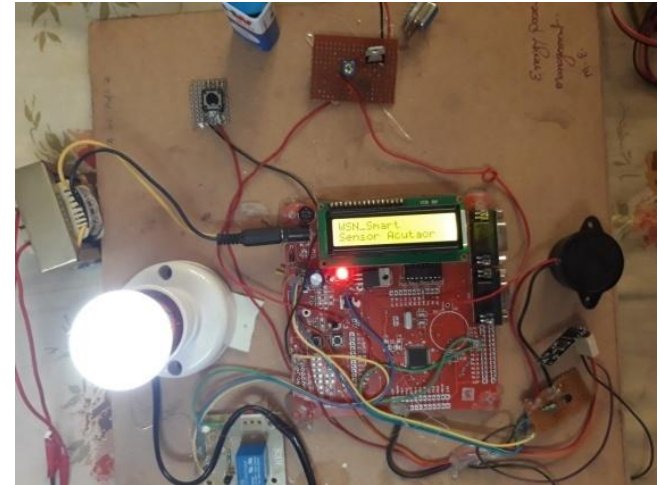

The below figure shows when the voltage level is varying at $2893 \mathrm{v}$ and it is the normal voltage level only and when it in normal voltage level the LED bulb will be in on it is the indication of the voltage levels are in normal.

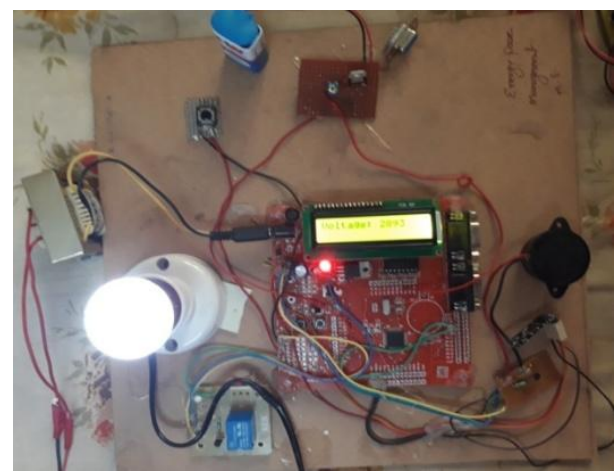

The below output figure and when the condition is in high voltage levels then the system will be in off condition because the possibilities of short circuit may take place and when the voltage varies in high levels then the LED bulb will be OFF and as well as the system too.

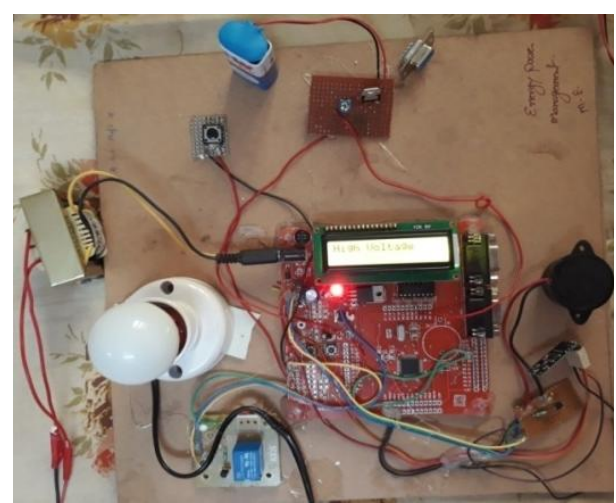

The below figure shows when the output voltage variations are at the exact voltage level of $585 \mathrm{v}$ and it is normal voltage level in this normally the all electrical appliances are in active but in kit the LED bulb will also in be in ON.

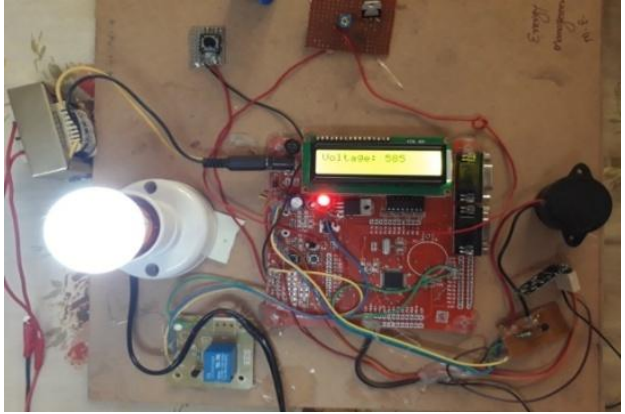

The above figure is taken when the system is short circuited and when the short circuit takes place. The short circuit is happened when the voltage levels are varying above the higher voltage levels or above the some fixed cut off voltage levels in this short circuit situations the buzzer alarm will be activated and the LED bulb will in OFF condition as well as the system is too in OFF condition.

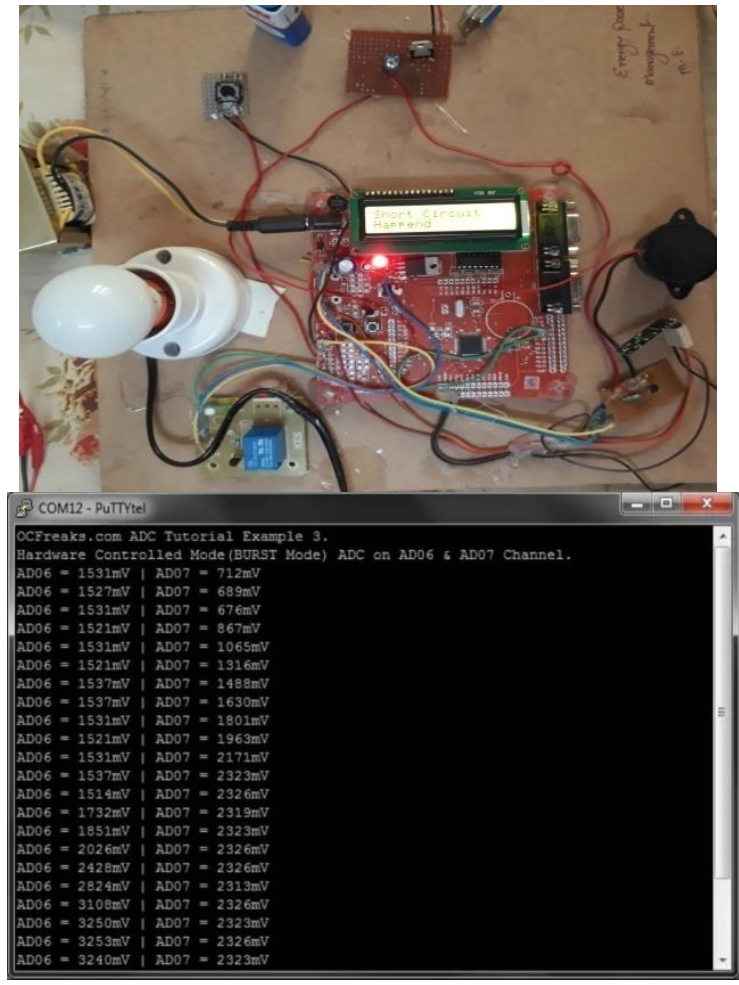

when the voltage levels are varying in various different voltage levels and in this it will displays all the conditions of the home electrical appliances and when short circuit happened and when the voltage levels are in high and any other conditions as shown in the above figure.

\section{CONCLUSION AND FUTURE SCOPE}


The project concludes that the power consuming system based on the wsn is nothing but the wireless sensor networks. In our proposed system we focus on the power consumption and the security purposes and the protection of the electrical devices and this is totally developed and improved by the embedding in the wireless sensor networks in mainly home energy management systems.

This power consuming system is totally an unique technology which is developed in this system. This can be further enhancing by applying this or else by adding this to GSM we can monitor the data from anywhere in this world and by adding GPS to this we can find out the exact locations where the problem or some emergency is generated and similar to that by adding GPRS to this we can maintain the database and this is highly useful for the security purposes and mainly protection of devices and power consumptions in HEMS and this system is having the evergreen enhancements in further future generations.

\section{REFERENCES}

[1]. X. P. Liu, W. Gueaieb, S. C. Mukhopadhyay, W. Warwick, and Z. Yin, "Guest editorial introduction to the focused section on wireless mechatronics," IEEE /ASME Trans. Mechatronics, vol. 17, no. 3, pp. 397-403, Jun. 2012.

[2]. D. S. Ghataoura, J. E. Mitchell, and G. E.Matich, "Networking and application interface technology for wireless sensor network surveillance and monitoring," IEEE Commun. Mag., vol. 49, no. 10, pp. 90-97, Oct. 2011.

[3]. P. Cheong, K.-F. Chang, Y.-H. Lai, S.-K. Ho, I.-K. Sou, and K.-W. Tam, “A zigbeebased wireless sensor network node for ultraviolet detection of flame," IEEE Trans. Ind. Electron., vol. 58, no. 11, pp. 5271-5277, Nov. 2011.

[4]. J. Misic and V. B. Misic, "Bridge performance in a multitier wireless network for healthcare monitoring," IEEE Wireless Commun., vol. 17, no. 1, pp. 9095, Feb. 2010.

[5]. M. Erol-Kantarci and H. T. Mouftah, "Wireless sensor networks for cost efficient residential energy management in the smart grid," IEEE Trans. Smart Grid, vol. 2, no. 2, pp. 314-325, Jun. 2011.

[6]. ZigBee alliance examining Japan's new smart home recommendations (accessed on 8 Aug., 2012). [Online]. Available: http://www.smartmeters. news/3449-zigbee-alliance
[7]. The costs and benefits of smart meters for residential customers (accessed on 4Apr. 2012). [Online].Available: http. net/iee/Documents/IEE_BenefitsofSmart Meters_Final.pdf

[8]. L. Li, H. Xiaoguang, H. Jian, and $\mathrm{H}$. Ketai, "Design of new architecture of AMR system in Smart Grid," in Proc. 6th IEEE Conf. Ind. Electron. Appl., 2011, pp. 2025-2029.

[9]. E. Andrey and J. Morelli, "Design of a smart meter techno-economic model for electric utilities in Ontario," in Proc. IEEE-Electric Power Energy Conf., 2010, pp. 1-7.

[10]. D. Man Han and J. Hyun Lim, "Smart home energy management system using IEEE 802.15.4 and zigbee," IEEE Trans. Consumer Electron., vol. 56, no. 3, pp. 1403-1410, Aug. 2010.

[11]. N. Kamat, "Enabling an electrical revolution using smart apparent energy meters \& tariffs," in Proc. Аnnu. IEEE India Conf., 2011, pp. 1-4.

[12]. F. Benzi, N. Anglani, E. Bassi, and L. Frosini, "Electricity smart meters interfacing the households," IEEE Trans. Ind. Electron., vol. 58, no. 10, pp. 44874494, Oct. 2011.Kunold, M. Kuller, J. Bauer, and N. Karaoglan, "A system concept of an energy information system in flats using wireless technologies and smart metering devices," in Proc. IEEE 6th Int. Conf. Intell. Data Acquisition Adv. Comput. Syst., 2011, pp. 812-816.

[13]. Triacs-BT 138 Series, Philips Semiconductors (accessed on 8 Jan. 2012). [Online]. Available: http://docsasia.electrocomponents.com/webdocs/ 0b4b/0900766b80b4bf38.pdf

[14]. J. Han, C. S. Choi, and I. Lee, "More efficient home energy management system based on zigbee communication and infrared remote controls," IEEE Trans. Consumer Electron., vol. 57, no. 1, pp. 85-89, Feb. 2011. 
